ఠ Open Access Full Text Article

EDITORIAL

\title{
Are we underestimating the lifelong benefits of therapy for obstructive sleep apnea?
}

\author{
This article was published in the following Dove Press journal: \\ Nature and Science of Sleep \\ 18 March 2016 \\ Number of times this article has been viewed
}

\section{Alec M Berman \\ Saurabh S Thosar \\ Steven A Shea}

Oregon Institute of Occupational Health Sciences, Oregon Health and Science University, Portland, OR, USA
Correspondence: Steven A Shea

Oregon Institute of Occupational Health Sciences, Oregon Health and Science University, 3 I8I SW Sam Jackson Park Rd, Portland, OR 97239, USA

Email sheast@ohsu.edu
Obstructive sleep apnea (OSA) is a complex disorder involving the cardiovascular (CV), pulmonary, and metabolic systems. Characterized by marked daytime fatigue and reduced quality of life, OSA is independently associated with increased risk of hypertension, ${ }^{1}$ cardiovascular disease (CVD) ${ }^{2}$ including myocardial infarction (MI) ${ }^{3}$ and ischemic stroke, ${ }^{4}$ metabolic syndrome, ${ }^{5}$ and all-cause mortality. ${ }^{6}$ Currently, the most common treatment for OSA is continuous positive airway pressure (CPAP) during sleep, though its efficacy in reducing daytime fatigue and CVD risk factors depends largely on compliance to therapy, which is poor in the general population. ${ }^{7}$ Lamberts et $\mathrm{al}^{8}$ performed a large epidemiological study of OSA, using the Danish National Patient Registry (NPR; 4.5 million; including 25,389 people diagnosed with OSA), which confirmed associations between OSA and risk of ischemic stroke and MI. Yet, that study failed to show that CPAP reduces the incidence of these adverse $\mathrm{CV}$ events. ${ }^{8}$ On the other hand, a more recent study, which examined the same Danish NPR across a very similar time period, revealed that in people with OSA, CPAP reduces all-cause mortality. ${ }^{9}$ This editorial evaluates these seemingly conflicting results, whereby CPAP appears to reduce mortality but not two of the largest contributors to mortality: stroke and MI.

Of interest, the study by Lamberts et al found that the associations between OSA and risk of $\mathrm{MI}$ and ischemic stroke occurred only in young people (aged 18-49 years) ${ }^{8}$ However, the prevalence of OSA in this sample was only $0.7 \%$, which is lower than in most other random populations $(3 \%-7 \%) .{ }^{10}$ Thus, many people with undiagnosed OSA likely contributed to the NPR control group, thereby biasing toward the null hypothesis and perhaps explaining the lack of an OSA effect in the older groups. Additionally, these authors were unable to find an effect of CPAP on stroke or MI incidence in any agegroup. However, they do suggest that use of CPAP in the younger population with high $\mathrm{CV}$ risk warrants further investigation. This seems reasonable, especially considering possible benefits of CPAP on symptoms of daytime sleepiness, ${ }^{11}$ plus the known $\mathrm{CV}$ benefits of CPAP, including reductions in both nocturnal and daytime blood pressure. ${ }^{12-14}$ Thus, starting therapy earlier in life has a greater potential to reduce the long-term effects of OSA on the CV system, including reducing the burden of hypertension. ${ }^{15}$ Should CPAP also be recommended for older people with OSA for CV outcomes alone? Lamberts et $\mathrm{al}^{8}$ claim that OSA may have less of a role in the development of CVD in the elderly because the emergence of other CV risk factors, including hypertension, may attenuate the relative contribution of OSA to MI and stroke. However, given the 
findings by Jennum et al, ${ }^{9}$ we believe a reinterpretation is warranted. This newer analysis revealed that CPAP therapy improves survival rate by approximately $30 \%$ in middle-aged and elderly men. ${ }^{9}$ Furthermore, two main limitations of this study may have resulted in an underestimate of the benefits of CPAP, as partly acknowledged by these authors. First, there was no information on the severity of sleep apnea (eg, the apnea-hypopnea index [AHI]). Since people with more severe symptoms are more likely to be treated, we contend that the group that received CPAP likely had higher OSA burden at the onset of the study. If the disease burden was higher and yet survival improved, then the benefits of CPAP would be underestimated. Second, there was no information on CPAP adherence: if adherence was poor yet survival improved, this would also underestimate the potential benefit of consistently used CPAP.

Additionally, Jennum et al failed to find an effect of CPAP in the younger cohort (aged 20-39 years) and in women of any age. But, given the protective $\mathrm{CV}$ effect female sex has prior to menopause, ${ }^{16}$ and the relatively low inherent risk of dying in the young, we would not expect CPAP therapy to affect mortality rates in populations with such low vulnerability (given the short duration of the study relative to life expectancy).

Taken together, we feel these studies provide strong evidence for the benefits of CPAP therapy across the life spans of people with OSA. In the young, CPAP reduces hypertension and may reduce the risk of an early-life adverse CV event. ${ }^{8}$ In middle-aged and elderly people with OSA, CPAP improves overall survival possibly via similar effects on the CV system. ${ }^{9}$ Such beneficial effects of CPAP could presumably be extrapolated to any other therapy that reduces the AHI. There are numerous other emerging therapies for $\mathrm{OSA}^{17}$ and great effort to improve adherence to CPAP therapy. ${ }^{18}$ Thus, future clinical trials of therapies for OSA ideally should employ large population approaches, and include randomized comparative-effectiveness trials, or placebo-controlled trials (eg, The Apnea Positive Pressure Long-term Efficacy Study). ${ }^{19}$ Additionally, incorporation of information on adherence to therapy, plus important health status indicators such as blood pressure, AHI, and body mass index will aid investigation of the associations between OSA disease burden, CV risk, and the effect of therapy on survival.

\section{Disclosure}

The authors report no conflicts of interest in this work.

\section{References}

1. Lavie P, Herer P, Hoffstein V. Obstructive sleep apnoea syndrome as a risk factor for hypertension: population study. BMJ. 2000; 320(7233):479-482.

2. Shahar E, Whitney CW, Redline S, et al. Sleep-disordered breathing and cardiovascular disease: cross-sectional results of the Sleep Heart Health Study. Am J Respir Crit Care Med. 2001;163(1):19-25.

3. Hung J, Whitford EG, Parsons RW, Hillman DR. Association of sleep apnoea with myocardial infarction in men. Lancet. 1990; 336(8710):261-264.

4. Yaggi HK, Concato J, Kernan WN, Lichtman JH, Brass LM, Mohsenin V. Obstructive sleep apnea as a risk factor for stroke and death. N Engl J Med. 2005;353(19):2034-2041.

5. Coughlin SR, Mawdsley L, Mugarza JA, Calverley PM, Wilding JP. Obstructive sleep apnoea is independently associated with an increased prevalence of metabolic syndrome. Eur Heart J. 2004;25(9): 735-741.

6. Marshall NS, Wong KK, Liu PY, Cullen SR, Knuiman MW, Grunstein RR. Sleep apnea as an independent risk factor for all-cause mortality: the Busselton Health Study. Sleep. 2008;31(8):1079-1085.

7. Weaver TE, Grunstein RR. Adherence to continuous positive airway pressure therapy: the challenge to effective treatment. Proc Am Thorac Soc. 2008;5(2):173-178.

8. Lamberts M, Nielsen OW, Lip GY, et al. Cardiovascular risk in patients with sleep apnoea with or without continuous positive airway pressure therapy: follow-up of 4.5 million Danish adults. J Intern Med. 2014;276(6):659-666.

9. Jennum P, Tønnesen P, Ibsen R, Kjellberg J. All-cause mortality from obstructive sleep apnea in male and female patients with and without continuous positive airway pressure treatment: a registry study with 10 years of follow-up. Nat Sci Sleep. 2015;7:43-50.

10. Punjabi NM. The epidemiology of adult obstructive sleep apnea. Proc Am Thorac Soc. 2008;5(2):136-143.

11. Marshall NS, Barnes M, Travier N, et al. Continuous positive airway pressure reduces daytime sleepiness in mild to moderate obstructive sleep apnoea: a meta-analysis. Thorax. 2006;61(5):430-434.

12. Lozano L, Tovar JL, Sampol G, et al. Continuous positive airway pressure treatment in sleep apnea patients with resistant hypertension: a randomized, controlled trial. J Hypertens. 2010;28(10): 2161-2168.

13. Sharma SK, Agrawal S, Damodaran D, et al. CPAP for the metabolic syndrome in patients with obstructive sleep apnea. $N$ Engl J Med. 2011;365(24):2277-2286.

14. Martínez-García MA, Capote F, Campos-Rodriguez F, et al. Effect of CPAP on blood pressure in patients with obstructive sleep apnea and resistant hypertension: the HIPARCO randomized clinical trial. JAMA. 2013;310(22):2407-2415.

15. Staessen JA, Wang JG, Thijs L. Cardiovascular protection and blood pressure reduction: a meta-analysis. Lancet. 2001;358(9290):1305-1315.

16. Kim C, Cushman M, Khodneva Y, et al. Risk of incident coronary heart disease events in men compared to women by menopause type and race. J Am Heart Assoc. 2015;4(7). pii: e001881.

17. Weaver TE, Calik MW, Farabi SS, et al. Innovative treatments for adults with obstructive sleep apnea. Nat Sci Sleep. 2014;6:137-147.

18. Engleman HM, Wild MR. Improving CPAP use by patients with the sleep apnoea/hypopnoea syndrome (SAHS). Sleep Med Rev. 2003;7(1):81-99.

19. Kushida CA, Nichols DA, Holmes TH, et al. Effects of continuous positive airway pressure on neurocognitive function in obstructive sleep apnea patients: The Apnea Positive Pressure Long-term Efficacy Study (APPLES). Sleep. 2012;35(12):1593-1602. 
Dove Medical Press encourages responsible, free and frank academic debate. The content of the Nature and Science of Sleep 'Editorial' section does not necessarily represent the views of Dove Medical Press, its officers, agents, employees, related entities or the Nature and Science of Sleep editors. While all reasonable steps have been taken to confirm the content of each Editorial, Dove Medical Press accepts no liability in respect of the content of any Editorial, nor is it responsible for the content and accuracy of any Editorial.

Nature and Science of Sleep

\section{Publish your work in this journal}

Nature and Science of Sleep is an international, peer-reviewed, open access journal covering all aspects of sleep science and sleep medicine, including the neurophysiology and functions of sleep, the genetics of sleep, sleep and society, biological rhythms, dreaming, sleep disorders and therapy, and strategies to optimize healthy sleep. The journal welcomes

\section{Dovepress}

original research, clinical \& epidemiological studies, reviews \& evaluations, case reports and extended reports. The manuscript management system is completely online and includes a very quick and fair peerreview system, which is all easy to use. Visit http://www.dovepress.com/ testimonials.php to read real quotes from published authors

Submit your manuscript here: http://www.dovepress.com/nature-and-science-of-sleep-journal 